\title{
A View on the Piano Music Culture from the Musical Form and Cultural Thoughts of the Chinese and Foreign Piano Works
}

\author{
Chunxiao Li \\ Henan Vocational Art College, China
}

Keywords: Harmony; National Culture; Historical Background.

\begin{abstract}
Piano music culture is broad and profound. This paper discusses that the piano music is a fusion of various cultures from the four aspects of musical aesthetics, national culture, historical background and inner emotion, and further deepens the understanding and concern of the piano music culture through the analysis of the musical form and cultural thoughts of Chinese and foreign piano works.
\end{abstract}

\section{Introduction}

As a kind of art which transcends time and space, and a kind of highly abstract art in the field of spirit, music has been formed and developed and improved gradually in people's thinking consciousness and living space. Piano music, as a branch of music art, interprets the art works with different times, regions, styles and humanities, and shows the charm of art. It benefits the aesthetics, philosophy, literature, and blends into the original, pure emotion to integrate the Chinese and Western music culture.

\section{The aesthetic thought of piano music - harmony}

Since we entered the new century, "harmony" is the most heard vocabulary. As a spiritual solvent to enhance the mutual communication on consciousness and emotion between people, it has become a fresh impetus to carry forward our national spirits. As an important factor in ideology and superstructure, music art also shows the charm of harmony in its formation and development of esthetic thought.

Tracing back to the birthplace of European music - Ancient Greek, the theory of music harmony first bred there. From the 6th century BC to the 4th century BC, the Pythagorean School put forward the view that "Music is the harmonious unity of opposites" from the perspective of the harmony of number and the purification of the feelings. Moreover, the music thoughts under the influence of medieval theology also put the harmony as the standard of beauty. The aesthetic essence of music harmony theory was also explored from the view of "Emotional harmony and mental harmony" in $17^{\text {th }}$ century. In the piano field, the works of various periods also demonstrated this view in different degrees. For example, in Baroque period, Bach's piano work “The Well-Tempered Clavier” had used the polyphony to integrate the Germany- advocated rationalism and mathematical rationalism in the first half of the 18th century, so that the music could develop regularly and smoothly in a complex but coherent state; in classical period, Mozart's piano sonata had rebuilt the harmonious beauty of music with a distinctive musical style, natural and harmonious melody, as well as delicate emotions; in romantic period, the "Scherzo" of Chopin had attributed the many contrasting factors of music to harmony so that perceptual and rational could be unified, and then the essence of harmonic theory was extracted, which sublimed the aesthetics thoughts with several centuries experience.

In the Chinese history of music aesthetics, according to the "Discourse on Zhou Sate", Mugong Shan and Zhoujiu Ling put forward the idea of music harmony from the auditory psychological aspect of music, and also put forward the thinking mode of "sound harmony - heart harmony - human harmony - political harmony" from the aesthetic evaluation. In the end of the Spring and Autumn, with the emergence of hundreds schools of thought, the "Perfect" of Confucianism which developed the requirements of "harmony" in music became the source of aesthetic standards in Chinese piano 
music. More than that, Xi Zhu in the Southern Song Dynasty and Shangying Xu in the late Ming and early Qing dynasties proposed the musical aesthetic standards of "harmony" respectively in "Ziyang Qinming” and "Xishan Qinkuang”. Thus, "harmony" had always been the aesthetic attitude for thousands of years in China. From a certain point of view, "Good" and "Beauty" mainly focused on the art form, and emphasized the effect of musical works on the progress and development of human society, which meant that people's political and moral standards (good) could be used as the standard of evaluation on the art form of music (beauty). "Harmony" focused on the artistic connotation. On one hand, it inherited and summarized the previous theory of music harmony, and advocated the perfect combination of music work, life practice and consciousness concepts. On the other hand, from the philosophical and ethical ideas, the "harmony" of Confucianism was reflected - The emotional performance of music should be moderated, so that the internal emotional experience and external performance of music aesthetics could maintain a harmonious state.

Since Yuanren Zhao published China's earliest piano works - "March of Peace" in 1915, the creation of Chinese piano music had opened a new chapter of harmony in thinking and creation. Lvting He’s "Shepherd Boy’s Piccolo” was dealt with counterpoint to the folk songs, which not only reflected Bach's style in the Baroque period from the creation technique, but also reflected the Pythagorean view. In the 60s-70s of the $20^{\text {th }}$ century, the adapted piano works "Flute And Drum At Sunset”, "Glowing Red Morningstar Lilies" and "Liuyang River" not only enriched the connotation of the music creation with different backgrounds and life practices, but expressed the soft and beauty of the melody of Chinese music with different national modes and styles, which was the reappearance of the western aesthetic standard "the harmony of perceptual and mental" in the seventeenth century.

To sum up, both the "harmony theory" of western and the "harmony" of China all played a unique role in the aesthetic category of music. Although containing with different ideological and cultural, they had the common developing trend: the art form and art content were getting better and better.

\section{The lifeline of piano music development - national culture}

Piano music culture is broad and profound. China's piano culture is deeply rooted in the traditional folk customs of China. After nearly a century of development and the tireless efforts of several generations of Chinese musicians, Piano music has taken root and sprouted in China's vast expanse of land and gradually become an important part of Chinese modern music art. The tremendous amount of folk songs in China not only provides inexhaustible music material for Chinese piano composers, but also inspires them to explore their own piano works.

"One Hundred of Birds Making Pilgrimage to Pay Homage to Phoenix" is a piano music composed by Jianzhong Wang according to the original folk Suona Music. Based on the E Gong mode, this music uses different sound types to simulate a variety of birds chirping, which endows a three-dimensional effect on the bright suona sound and the pure ethnic characteristics. The use of fourth and octave interval, the polyphonic writing technique and the broader range, make up the deficiencies of Chinese piano works such as stronger monophonic melody and relatively defective inner voices, and also break through original range limitations of suona A-d $\mathrm{d}^{3}$.

The western piano culture also has experienced a history of erosion and cultural reproduction from the origin to the development. Although national music culture is not emerged with the birth of the piano music, it gradually roots out along with the progress of human civilization, which is full of vitality just like the lives of young people.

Chopin, a European romantic poet in nineteenth century, as well as a representative of the national piano music, had spent all his life to write the works with the Polish local characteristics and the spirit of national resistance, such as "Mazurka", "Etude (revolution)" and "Polonez in A-flat Major (Hero)".

Thus, the classical piano works with national style are developing and strengthening themselves in the development of Eastern and Western culture, and meanwhile taping its new potential in creating ideas and techniques with different regions and factions, which is also the impetus for the further 
development of the piano music on the basis of adhering to the inherent characteristics of the nationality.

\section{The elements of piano music growth - history background}

Adorno once pointed out: "The art of work depends on the state of the world, that is to say, the historical context and the other people of art are their conditions.” Indeed, different historical backgrounds have a significant impact on the formation of the humanistic ideas and the creation style of the works.

The last five Beethoven Piano Sonatas were written after the failure of the French revolution. The darkness of the feudal restoration, the destruction of the bourgeois national concept, and the missed lover and happiness, almost pushed the Beethoven's spiritual world to the brink of the abyss. But his indomitable spirit finally defeated the darkness of the reality. He integrated his beautiful aspiration to the future world into his works, which showed that he devoted all his will (to achieve victory through the struggle) to such a work.

Chinese piano work "Erquan Yingyue" was a song with a high cultural value which was adapted by Mr. Wanghua Chu based on the Erhu works of Yanjun Hua. The whole song told a miserable and bumpy life experience of people at the bottom through the transformation of the rhythm, with a trilogy type structure (lento, andante, adagio).

In the first part of the music, there are a total of three theme and variations, which not only deepen the theme of the whole song, but also express a tragic scene of family decline and lacking of food and clothes in different ways. The second part is the climax of the music. The transition from lento to andante, the emergence of intensive sound type, and the pentatonic scale moving forward in the form of four parts harmony, all set off by contrast the storm-like passion of the author. The third part is the reproduction and variation of the first two parts. The andante return to the original tempo, but the music is more soft and plaintive, which is adagio cantabile. The real life experience is manifested exactly in this work, which make people deeply moved.

Thus, the historical environment directly affects the author's creative consciousness. Although "Erquan Yingyue" is an adapted piano works, the main idea to strive the performance is not changed. With the help of the piano performing form, more profound artistic connotation is given to this work, so that the cruel reality of the old society can be reflected with a new form in the new field. Despite the fact that Beethoven's works are alienated from the reality, the undeniable historical background makes him to develop music by using the contradiction between reality and ideal. Therefore, it is important to understand the background of different times so as to grasp the profound connotation of any piano works.

\section{The cornerstone of piano music culture - intrinsic emotion}

The inner emotion is the advanced sensibility hidden in the deep emotional structure of the piano works, and it is the basic requirement for the creation of all kinds of artistic genres and works.

According to the psychology, people's emotion can be divided into three parts: perception, emotion and consciousness, so are the music. Perception is the prerequisite for understanding the materialized piano works; people's consciousness is the re-creation of the non semantic piano works; emotion refers to the inner emotional experience, which is the bridge to connect perception and consciousness. Therefore, the inner emotion is the key to the performance mechanism of the piano music culture.

First of all, the emotional experience is controlled by the brain function, while the genetic code is the physiological and morphological characteristics of human's mind, with various functions such as the receiving, processing and storage of information, as well as self-regulation and self organization. Therefore, all kinds of mental activities will come into being different emotional models through the genetic code and according to their own perception. These emotional patterns have a certain emotional colors due to their own perception. For instance, in the spring and autumn period, the Laozi 
and Zhuangzi School advocated the opinions of "Da Yin Xi Sheng” and "Sounds of Nature". Although they were trying to exclude the perceptual experience, and advocating the comprehension the "Tao follows nature", such a mental state had already included the subjective emotional color, and mapped it out.

Secondly, the inner feelings originate from the people's living space and have a strong sociality. In the field of music, it indicates that the social and emotional life changes caused by the transformation of the world are the most fundamental driving force for the change of the musical situation. Confucius, a representative of the Confucian school, also expresses his inner feelings with the help of natural objects in his life. Therefore, the social emotional experience has become the cornerstone of building a piano music culture.

In the process of writing or playing the piano works, the powerful emotions are permeated into the music works so as to make people to feel the state of "The identity about the matter and me", so that the piano music may have great vitality and become immortal spirit treasure just like the history of human culture.

\section{Conclusion}

In summary, piano music has become a kind of culture, which breaks through the boundary of the region to integrate the essence in the exchange of eastern and western art. This culture breaks through the shackles of thinking, so that the non-semantic and non-conceptual music language could seek a unique understanding and feeling in people's conventional emotional world. Moreover, the pursuits of creative thinking of national style, and the absorption of the profound connotation of other disciplines, also promote the development of the piano music. Therefore, whether it is the ancient and mysterious east, or the modern and open west, will open a door for piano art, so that the more profound music culture could walk hand in hand with us in the fast-forward era.

\section{References}

[1] Hailin Xiu, Xiaoping Luo. The general theory of music aesthetics [M]. Shanghai: Shanghai Conservatory of Music Publishing House, 1999.

[2] Guozhu Wu, Xiaoguang Gao. Piano Art Exhibition [M]. Beijing: Olympic Publishing House, 1997.

[3] Hongdao Zhang. European Music History [M]. Beijing: People’s Music Publishing House, 1982.

[4] The Editorial Department of People's Music Publishing House. The Style and Genre of Western Music [M]. Beijing: People’s Music Publishing House, 1995. 